\title{
Prevalence and Predictors of Vitamin D Inadequacy: A Sample of 2,547 Patients in a Mediterranean Country
} Sara Salman ${ }^{1,2}$, Mariam Khouzami ${ }^{3,2}$, Mirvate Harb ${ }^{4,2}$, Bouchra Saleh ${ }^{4,2}$, Mohammad O. Boushnak ${ }^{5}$,
Mohamad K. Moussa $^{5}$, Zeina H. Mohsen 6,

1. Department of Laboratory Medicine, Zahraa Hospital University Medical Center, Beirut, LBN 2. Department of Clinical Pathology, Faculty of Medical Sciences, Lebanese University, Beirut, LBN 3. Department of Laboratory Medicine, Habanjar Medical Center, Beirut, LBN 4. Department of Laboratory Medicine, Rafik Hariri University Hospital, Beirut, LBN 5. Department of Orthopedic Surgery, Faculty of Medical Sciences, Lebanese University, Beirut, LBN 6. Department of Clinical Pathology, Rafik Hariri University Hospital, Beirut, LBN

Corresponding author: Zeina H. Mohsen, zeinamohsen@outlook.com

\section{Abstract}

\section{Background}

The aim of this retrospective study was to identify prevalence and risk factors for vitamin D inadequacy in a sunny Mediterranean country.

\section{Methods}

Results of 2,547 patients aged 19 to >60 years were included in this study. Data were derived from the laboratory database at Rafik Hariri University Hospital, Beirut, Lebanon, over a period of two years (20162017). Data included patient's age, gender, date of test, and vitamin D level. Females were questioned through phone call for marital status, parity, and veiling.

\section{Results}

The prevalence of vitamin D inadequacy was $83.5 \%$ overall, $86.4 \%$ in males, and $82.3 \%$ in females. At a cutoff of $20 \mathrm{ng} / \mathrm{mL}$, vitamin D deficiency affected $63 \%$ of the studied population. A significant association was observed between vitamin D and age. The highest prevalence (71.2\%) was found in females in the age group of 19-39 years, while no significant correlation with age was observed in males. Vitamin D levels were lower in veiled women (mean $25(\mathrm{OH}) \mathrm{D}=17.9 \mathrm{ng} / \mathrm{mL}$ ) compared to non-veiled women, although this difference was not significant. In addition, vitamin D inadequacy does not show a significant association with gender, parity, marital status, and season of the year.

\section{Conclusion}

Review began 04/23/2021 Review ended 05/06/2021 Published 05/07/2021

\section{๑) Copyright 2021}

Salman et al. This is an open access article distributed under the terms of the Creative Commons Attribution License CC-BY 4.0., which permits unrestricted use, distribution, and reproduction in any medium, provided the original author and source are credited.
The high prevalence of vitamin D inadequacy in our study in both males and females of all age groups calls for urgent actions at the national level to increase awareness in the population and to prevent the serious complications of vitamin D deficiency in all patients, especially those who are at a high risk.

Categories: Endocrinology/Diabetes/Metabolism, Orthopedics, Epidemiology/Public Health

Keywords: vitamin-d deficiency, vitamin d level, public awareness of vitamin d, epidemiology and public health, laboratory finding

\section{Introduction}

Vitamin D, the sunshine vitamin, is a hormone rather than a vitamin and is one of the primary regulators of calcium homeostasis in the body. Although a small amount of vitamin D is thought to be supplied from food, exposure of skin to the ultraviolet (UV) rays in sunlight is known to be the major source [1].

Extracellular calcium is essential for the functioning of many metabolic processes and neuromuscular activities and is of major importance for bone health [2-6]. Vitamin D deficiency is now recognized as a global epidemic.

In Middle Eastern countries, despite ample sunshine, several recent studies have shown a surprisingly high incidence of vitamin D deficiency in people aged 30-50 years [7], school children [8], elderly people [9], and postmenopausal osteoporotic women $[10,11]$. This is in large part explained by limited sun exposure due to cultural practices [12], dress codes, culinary habits, and very hot regions [4,7], and by prolonged breastfeeding without vitamin D supplementation [12]. Total body vitamin D stores can be assessed by measuring the serum concentration of total 25(OH)D (25-hydroxyvitamin D) [13]. 
Historically, vitamin D was measured by competitive binding methods, high-performance liquid chromatography (HPLC), and radioimmunoassay (RIA). RIA was considered the gold standard and has been used to establish reference ranges during the past decade. The reference method for vitamin D analysis has been liquid chromatography-mass spectrometry/mass spectrometry (LC-MS/MS), which can measure vitamin D2, vitamin D3, and D3 epimer separately, and through calculation, total vitamin D is reported [14].

Several United States Food and Drug Administration (FDA)-approved immunoassay methods are available, including quantitative chemiluminescent immunoassay (CLIA) methods. Several methods that measure total 25-hydroxy vitamin D and other hydroxylated vitamin D metabolites in human serum were developed [15].

Automated immunoassays are available for total vitamin levels and have improved in precision and accuracy due to market demands. There have been many published results of comparison studies between RIA methods and HPLC and between other immunoassay methods and HPLC. A more recent comparison shows better agreement between immunoassay methods and LC-MS/MS [16-22]. In immunoassays methods, most antibodies to 25(OH)D are known to cross-react with dihydroxylated, metabolites but interference in some assays was far greater than expected. This may be related to the anomalous behavior of exogenously added metabolites in these 25(OH)D methods [23].

The normal vitamin $\mathrm{D}$ range varies between populations and is dependent upon many factors. Despite the ongoing controversy regarding the definition of vitamin $\mathrm{D}$ deficiency, the most accepted definition of vitamin $D$ deficiency in adults is defined as a serum $25(\mathrm{OH}) \mathrm{D}$ level $<20 \mathrm{ng} / \mathrm{mL}$, insufficiency as a serum 25(OH)D level of 20-30 ng/mL, and sufficiency as a serum 25(OH)D level above $30 \mathrm{ng} / \mathrm{mL}$ [13].

Evidence indicates that low vitamin D levels lead to increased rates of rickets, osteomalacia, and altered bone mass. Consistent predictors of low levels are older age, female gender, multi-parity, winter season, conservative clothing style, low socioeconomic status (SES), and urban living [8,24-26].

Vitamin D inadequacy is highly prevalent in Lebanon in all age groups, even in young individuals $[27,28]$. The aim of this study is to estimate the prevalence of vitamin D inadequacy in a sample of the Lebanese population to study the correlation between vitamin D deficiency and other factors such as gender, age, marital status, parity, season of the year, and dress style, and to compare these finding with other conducted studies.

\section{Materials And Methods \\ Data collection}

A retrospective study was conducted at Rafik Hariri University Hospital (RHUH), a central governmental hospital in Beirut, Lebanon. The data was obtained from the laboratory database at the hospital through the IT Department after approval of the head of the laboratory division at the hospital. Institutional Review Board approval was obtained prior to the initiation of the study.

In this study, all vitamin D tests conducted over a period of two years (2016-2017) were taken. Lebanese patients aged $>18$ years were included. Age, gender, VITAMIN D level, and date of the test for each patient were recorded. Data regarding dress style, marital status, and multi-parity were obtained from female patients through a questionnaire conducted via phone call.

\section{Laboratory analysis}

Samples were collected according to the RHUH standard operating procedure (SOP) for blood collection using serum separator tubes or plain tubes. Interferences with testing, mainly hemolysis, icterus, and lipemia, were eliminated. The level of 25(OH)D was measured using the ARCHITECT i1000SR platform (Abbott Laboratories, Abbott Park, IL, USA) in 2016 and the cobas ${ }^{\circledR} 6000$ platform (F. Hoffmann-La Roche AG, Basel, Switzerland) in 2017.

The ARCHITECT i1000SR 25(OH)D assay is a one-step delayed fully automated chemiluminescent microparticle immunoassay (CMIA). The cobas 6000 uses a competitive electrochemiluminescence (ECL) method for the measurement of 25(OH)D.

\section{Statistical analysis}

The chi-square test of independence was used to determine if there is a significant relationship between two categorical variables, and $\mathrm{p}$-values $<0.05$ were considered significant. Statistical analysis was performed using Microsoft Excel software.

\section{Results}

Characteristics of the study population 


\section{Cureus}

A total of 2,547 participants were included in this study, with 1,810 females (71.06\%) and 737 males (28.94\%). The mean age was 48.91 years $(S D=16.53$; range: $19-99$ years). Participants aged $>60$ years constituted $27.17 \%$ of the sample. The majority of females were veiled (75.34\%) and multiparous (62.44\%) (Table 1). Furthermore, $47.2 \%$ of vitamin D levels were tested during the fall-winter season and $52.37 \%$ during the spring-summer season.

\begin{tabular}{|c|c|c|}
\hline Variable & $\mathbf{n}$ & $\%$ \\
\hline \multicolumn{3}{|l|}{ Age, years } \\
\hline $19-39$ & 861 & $33.80 \%$ \\
\hline $40-59$ & 994 & $39.03 \%$ \\
\hline$>60$ & 692 & $27.17 \%$ \\
\hline \multicolumn{3}{|l|}{ Gender } \\
\hline Female & 1810 & $71.06 \%$ \\
\hline Male & 737 & $28.94 \%$ \\
\hline \multicolumn{3}{|c|}{ Dress style (females) } \\
\hline Veiled & 825 & $75.34 \%$ \\
\hline Non-veiled & 270 & $24.66 \%$ \\
\hline \multicolumn{3}{|l|}{ Marital Status } \\
\hline Single & 216 & $19.96 \%$ \\
\hline Married & 866 & $80.04 \%$ \\
\hline \multicolumn{3}{|c|}{ Parity (females) } \\
\hline Nulliparous & 297 & $27.47 \%$ \\
\hline Uniparous & 109 & $10.08 \%$ \\
\hline Multiparous & 675 & $62.44 \%$ \\
\hline
\end{tabular}

\section{TABLE 1: Distribution of the study population by sociodemographic characteristics}

\section{Vitamin D status of the study population by gender}

The majority (62.1\%) of men were vitamin D deficient, $24.3 \%$ were insufficient, and only $13.6 \%$ were sufficient. Almost similar rates of vitamin D deficiency (63.3\%) and insufficiency (19\%) were observed in females compared to males (Figure 1). The mean vitamin D level was $18.4 \mathrm{ng} / \mathrm{mL}$ in males and $18.6 \mathrm{ng} / \mathrm{mL}$ in females. This difference is not statistically significant $(p=0.086)$. 


\section{Cureus}

1400

deficient

1200

1000

嵩

号 800

แั

ذ 600

ह 400

200

0
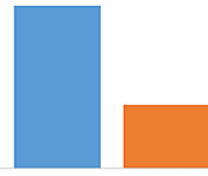

Males
Insufficient

$\square$ Sufficient
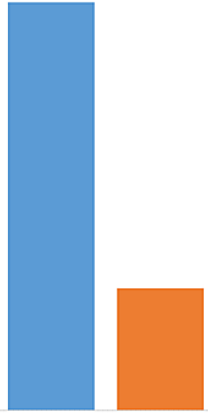

Females

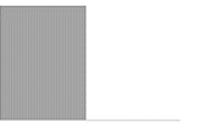

FIGURE 1: Distribution of individuals tested according to vitamin D status and gender $(p=0.086)$

\section{Vitamin D status of the study population by age}

The prevalence of low vitamin D status was highest in men in the age group of 40-59 years (64.5\%), whereas in women it was highest in the age group of $19-39$ years $(71.2 \%)$.

The mean values of serum 25(OH)D level by age, for males and females separately, are shown in Table 2, with the difference across all age groups being significant $(\mathrm{p}<0.001)$ in the total population and in females but not significant in males $(\mathrm{p}=0.075)$.

Men aged $>60$ years and women aged 19-39 years of age had the lowest mean value of 25(OH)D with values of 17.4 and $16.2 \mathrm{ng} / \mathrm{mL}$, respectively. 


\section{Cureus}

\begin{tabular}{|c|c|c|c|c|c|c|}
\hline & \multirow{2}{*}{$\mathbf{n}$} & \multirow{2}{*}{$\begin{array}{l}25(\mathrm{OH}) \mathrm{D}(\mathrm{ng} / \mathrm{mL}) \\
\text { Mean } \pm \text { SD }\end{array}$} & \multicolumn{3}{|c|}{ 25(OH)D level (ng/mL) } & \multirow{2}{*}{$\mathrm{p}$-Value } \\
\hline & & & $<20$ & $20-29.9$ & $>30$ & \\
\hline \multicolumn{7}{|c|}{ Age, years } \\
\hline $19-39$ & 861 & $17.1 \pm 11.8$ & 582 (67.6\%) & 164 (19.05\%) & 115 (13.3\%) & \multirow{3}{*}{$<0.001$} \\
\hline $40-59$ & 994 & $18.3 \pm 11.8$ & 612 (61.5\%) & $242(24.3 \%)$ & $140(14.1 \%)$ & \\
\hline$>60$ & 692 & $20.7 \pm 15.8$ & 409 (59.1\%) & 117 (16.9\%) & $166(24 \%)$ & \\
\hline Total & 2547 & $18.56 \pm 13.1$ & $1603(63 \%)$ & $523(20.5 \%)$ & $421(16.5 \%)$ & \\
\hline \multicolumn{7}{|l|}{ Male } \\
\hline $19-39$ & 218 & $19.7 \pm 10.6$ & $124(56.9 \%)$ & 57 (26.1\%) & 37 (17.0\%) & \multirow{3}{*}{0.0753} \\
\hline $40-59$ & 245 & $18.4 \pm 12$ & 158 (64.5\%) & 47 (19.2\%) & 40 (16.3\%) & \\
\hline$>60$ & 274 & $17.4 \pm 9.2$ & 176 (64.2\%) & $75(27.4 \%)$ & $23(8.4 \%)$ & \\
\hline Total & 737 & $18.4 \pm 10.7$ & $458(62.1 \%)$ & $179(24.3 \%)$ & $100(13.6 \%)$ & \\
\hline \multicolumn{7}{|l|}{ Female } \\
\hline $19-39$ & 643 & $16.2 \pm 12$ & 458 (71.2\%) & 107 (16.7\%) & $78(12.1 \%)$ & \multirow{3}{*}{$<0.001$} \\
\hline $40-59$ & 720 & $18.6 \pm 12.7$ & $436(60.6 \%)$ & $167(23.2 \%)$ & $117(16.2 \%)$ & \\
\hline$>60$ & 447 & $22 \pm 17.4$ & $251(56.1 \%)$ & 70 (15.7\%) & $126(28.2 \%)$ & \\
\hline Total & 1810 & $18.6 \pm 14$ & 1145 (63.3\%) & 344 (19\%) & $321(17.7 \%)$ & \\
\hline
\end{tabular}

TABLE 2: Vitamin D status by age and gender

Distribution of vitamin D status by age is represented in figures $2 a-2 c$. 


\section{Cureus}

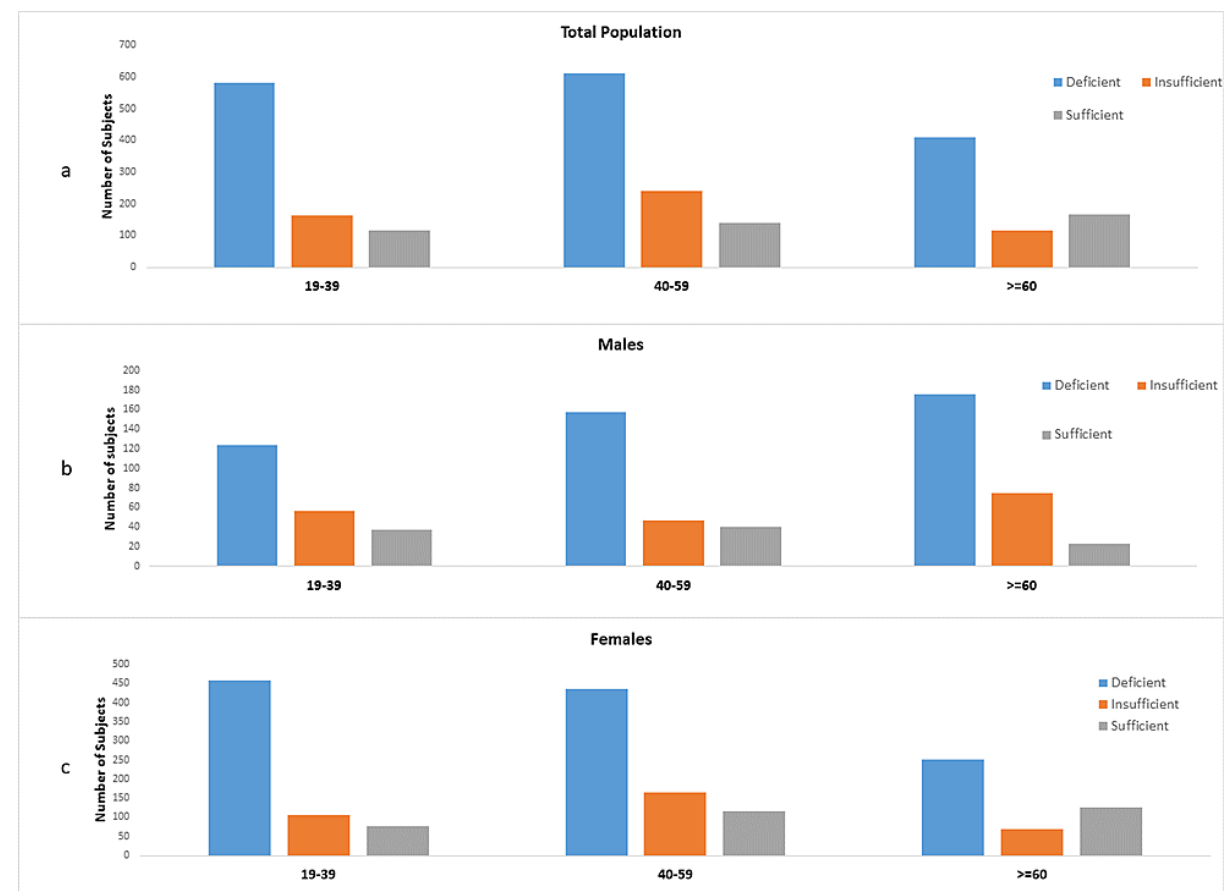

FIGURE 2: Distribution of individuals tested according to vitamin D status and age: (a) in the total population ( $p<0.001$ ), (b) in males ( $p$ $=0.075)$, and $(c)$ in females $(p<0.001)$.

\section{Correlation between vitamin $\mathrm{D}$ concentration and age}

A weak positive significant correlation between age and vitamin $D$ concentration was observed $(r=0.106 ; p$ $<0.001)$ and reflected mainly in females $(r=0.159 ; p<0.001)$, while no significant correlation was observed in males $(r=-0.042 ; p=0.075)$ (Figure 3). 


\section{Cureus}
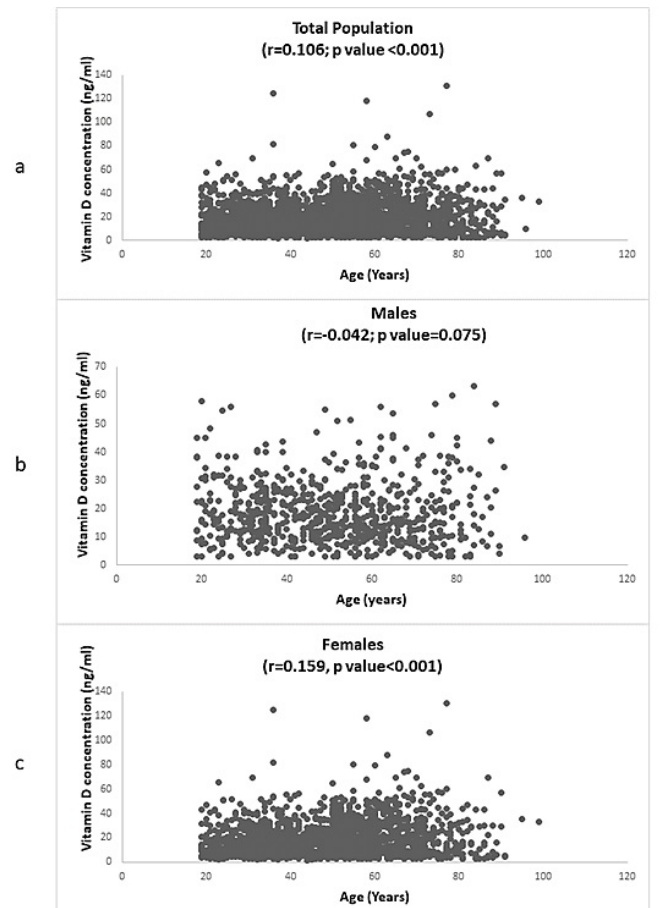

FIGURE 3: Correlation between vitamin D concentration and age: (a) in the total population, (b) in males, and (c) in females.

\section{Prevalence of low vitamin D status by selected variables}

Figure 4 shows the distribution of serum $25(\mathrm{OH}) \mathrm{D}$ concentrations in the three categories of study participants: 1,603 (63\%) were deficient, 523 (20.5\%) were insufficient, and 421 (16.5\%) were sufficient.

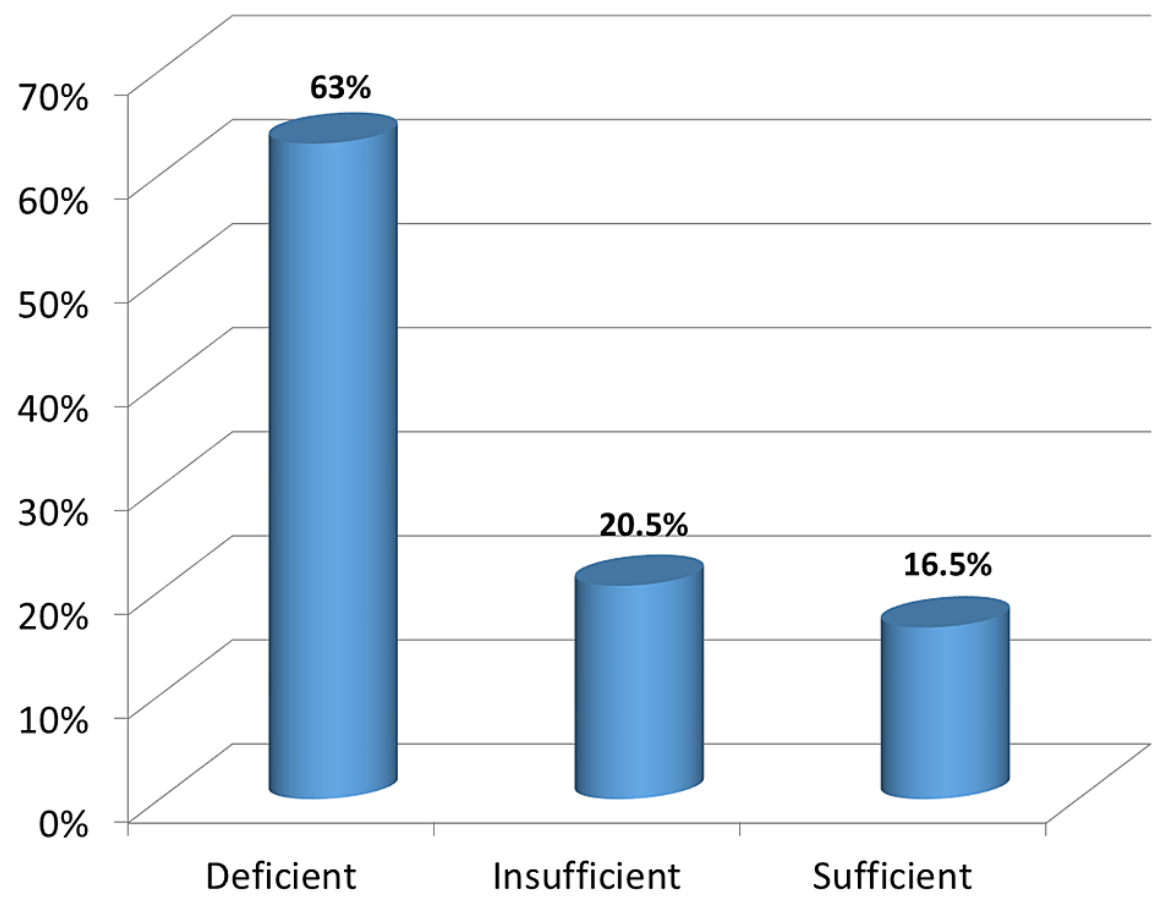

FIGURE 4: Distribution of the participants according to vitamin D levels. 


\section{Cureus}

The overall prevalence of low vitamin D status $(25(\mathrm{OH}) \mathrm{D}<30 \mathrm{ng} / \mathrm{mL})$ was $83.5 \%$. Table 3 shows the mean of $25(\mathrm{OH}) \mathrm{D}$ concentration and the prevalence rates of low vitamin D status in the study population by selected variables. Participants aged $>60$ years were less likely to have low vitamin D status (76\%), and this was significant as compared to other age groups $(\mathrm{p}<0.001)$. Females were less likely to have low vitamin $\mathrm{D}$ status (82.3\%) than males (86.4\%), although this difference was not significant $(\mathrm{p}=0.086)$. Low vitamin D status was less prevalent in spring-summer season (82.6\% and $82.3 \%$, respectively) as compared to fall-winter ( $83.5 \%$ and $85 \%$, respectively), with the difference being insignificant $(\mathrm{p}=0.94)$. Non-veiled women $(77.8 \%)$ were less likely to have low vitamin D status than veiled women (82.15\%), with the difference being insignificant $(\mathrm{p}=0.37)$. Single women $(74.54 \%)$ were less likely to have a low vitamin $\mathrm{D}$ level than married women $(81.64 \%)$, with the difference observed being insignificant $(\mathrm{p}=0.14)$. Uniparous women were less likely to have low vitamin D status (76.15\%) than nulliparous (79.12\%) and multiparous women (81.33\%), with the difference being insignificant $(\mathrm{p}=0.865)$.

\begin{tabular}{|c|c|c|c|}
\hline Variable & Mean 25(OH)D concentration $(\mathrm{ng} / \mathrm{mL}) \pm \mathrm{SD}$ & Prevalence of low $25(\mathrm{OH}) \mathrm{D}<30 \mathrm{ng} / \mathrm{mL}(\%)$ & p-Value \\
\hline Total & $18.56 \pm 13.1$ & $83.50 \%$ & \\
\hline Age, years & & & $<0.001$ \\
\hline $19-39$ & $17.1 \pm 11.8$ & $86.60 \%$ & \\
\hline $40-59$ & $18.3 \pm 11.8$ & $86 \%$ & \\
\hline$>60$ & $20.7 \pm 15.8$ & $76 \%$ & \\
\hline Gender & & & 0.086 \\
\hline Male & $18.4 \pm 10.7$ & $86.40 \%$ & \\
\hline Female & $18.6 \pm 14$ & $82.30 \%$ & \\
\hline Period of the year & & & 0.94 \\
\hline January-March & $17.57 \pm 12.35$ & $85 \%$ & \\
\hline April-June & $18.03 \pm 14.01$ & $82.6 \%$ & \\
\hline July-September & $19.66 \pm 12.7$ & $82.3 \%$ & \\
\hline October-December & $19.06 \pm 13.4$ & $83.5 \%$ & \\
\hline Dress style & & & 0.37 \\
\hline Veiled & $17.9 \pm 14.42$ & $82.15 \%$ & \\
\hline Non-veiled & $21.23 \pm 13.54$ & $77.8 \%$ & \\
\hline Marital status & & & 0.14 \\
\hline Single & $19.74 \pm 14.29$ & $74.54 \%$ & \\
\hline Married & $19.16 \pm 14.25$ & $81.64 \%$ & \\
\hline Parity & & & 0.865 \\
\hline Nulliparous & $18.74 \pm 13.68$ & $79.12 \%$ & \\
\hline Uniparous & $20.11 \pm 16.23$ & $76.15 \%$ & \\
\hline Multiparous & $19.39 \pm 14.18$ & $81.33 \%$ & \\
\hline
\end{tabular}

TABLE 3: Prevalence of low vitamin D status by selected variables

\section{Discussion}

Vitamin D inadequacy, emerging as a major health problem globally, is a highly prevalent condition, affecting people across all age groups $[4,29,30]$.

Despite the adequate sunshine in Middle Eastern countries and more particularly in Lebanon, the incidence of hypovitaminosis D is surprisingly high in all age groups, even in young individuals and osteoporotic women. 
The results of the present study show that in Lebanon, despite the sunny weather, there is a high prevalence of vitamin D inadequacy, with $83.5 \%$ of the population studied having serum $25(\mathrm{OH}) \mathrm{D}<30 \mathrm{ng} / \mathrm{mL}$. This prevalence is slightly higher than what was previously reported in several subgroups of the Lebanese population [7,28]. At a cut-off of $20 \mathrm{ng} / \mathrm{mL}$, vitamin D deficiency affects $63 \%$ of the studied population. In fact, using a cut-off of $20 \mathrm{ng} / \mathrm{mL}$, vitamin D deficiency affects $52 \%$ of Lebanese school children [8]. In addition, using a lower cut-off of $15 \mathrm{ng} / \mathrm{mL}, 74 \%$ of the young Lebanese population aged 30-50 years are affected [7].

Finally, in another study, using a cut-off of $30 \mathrm{ng} / \mathrm{mL}$, 84\% of postmenopausal osteoporotic Lebanese women have vitamin D insufficiency $[10,11]$.

The mean vitamin D in our study was $18.56 \pm 13.1 \mathrm{ng} / \mathrm{mL}$. These results were similar to those reported in previous studies on Lebanese elderly and adult populations that had also a mean of $10-30 \mathrm{ng} / \mathrm{mL}$ [31].

The reason for the high prevalence of vitamin D deficiency in Lebanon, and particularly in the studied population is multifactorial.

This study was performed on outpatients and inpatients at RHUH aged 19 years and older. The main independent predictor of vitamin D insufficiency in our study was age. Other predictors of hypovitaminosis D reported in different studies were female gender, inadequate dietary vitamin D intake, urban dwelling, veiling and parity in women [7], inadequate use of vitamin D supplements in postmenopausal women [10], dress code covering arms, high BMI, and low educational levels, while season, sun exposure, and dietary vitamin D were not.

Among the most surprising finding of the present study is the higher prevalence of vitamin D insufficiency among males (86.4\%) compared to females (82.3\%), although this difference was not statistically significant in our study ( $\mathrm{p}=0.086$ ). This finding is opposite to the results of most other studies where females were at a higher risk of developing low vitamin D levels [7,10,28,31,32]. However, a one-of-a-kind Lebanese study considering parameters such as age, sex, seasonal changes, and PTH levels [33] reported that males were at higher risk of being below the standard vitamin D cut-off of $20 \mathrm{ng} / \mathrm{mL}$; this can very well be attributed to the difference between male and female physiology and most importantly the gestational paradigm of women. Higher prevalence of vitamin D deficiency among males was also reported in some studies [34].

It has been suggested that an independent predictor for low vitamin D levels is multi-parity along with the lack of antenatal care [31]. In our study, multiparous women had a higher rate of vitamin D inadequacy (81.33\%) compared to nulliparous (79.12\%) and uniparous women $(76.15 \%)$. This difference was not proven to be significant in our study $(\mathrm{p}=0.865)$.

Low vitamin D status attributed to the traditional Islamic type of dressing has been reported previously [3538]. A study on Lebanese adult population has shown that veiled women had almost a three times higher prevalence of severe hypovitaminosis D [7] than non-veiled women. In agreement with the previous studies, the mean vitamin D level in our veiled women group (17.96\%) was lower than that of the non-veiled group (21.23\%), and the prevalence of vitamin D inadequacy was higher in veiled women (82.15\%) compared to non-veiled women (77.8\%), although the difference observed was not proven to be statistically significant.

It has been well established that vitamin D deficiency spares no age group. In our study, this deduction has been proven in all age groups where prevalence ranged between $76 \%$ and $86.6 \%$ in the ages 19 to $>60$ years. The highest number of deficient patients was in the age range of 40-59 years (612 patients having vitamin D level $<20 \mathrm{ng} / \mathrm{mL}$ ), though a higher prevalence of vitamin D deficiency was indicated in younger adults in the age group of $19-39$ years (67.6\% of patients in this age group having vitamin D level $<20 \mathrm{ng} / \mathrm{mL}$ and $86.6 \%$ having vitamin D level $<30 \mathrm{ng} / \mathrm{mL}$ ). In our study, the difference across all age groups was significant ( $p$ $<0.001$ ). These results correlate with results reported in studies across MENA (Middle East and North Africa region). In Lebanon, several studies have been associated with vitamin D deficiency in different age groups. This deficiency prevailed in several pediatrics [8], adults [7], and elderly [31] populations. In Iran, younger age was a predicament for low vitamin D levels, as shown in a study by Kaykhaei et al. [39]. In another Iranian study, the prevalence of vitamin D deficiency was compared among different age groups and was higher in the younger age group [40]. In Palestine, older age was a predictor of low vitamin D levels as was shown in North African countries such as Morocco and Tunisia [33]. Similar results of all age groups results were found in Kuwait, Jordan, and UAE [31].

All age groups may face deficiency for different reasons such as dietary intake in the case of children [8] and pregnant women [41] or due to traditional wear [28] and ethnicity where Muslim women were shown to be at higher risk than Christian women in terms of simple veiling [10].

The effect of seasonal sunlight exposure on vitamin D status has been well documented [42-44], confirming the importance of sun exposure in the synthesis of vitamin D.

The findings of this study indicate variations in mean serum 25(OH)D levels across the various seasons. The 
serum 25(OH)D level in the winter months was at the lowest level (mean 25(OH)D $=17.5 \mathrm{ng} / \mathrm{mL}$ ) versus the summer months (mean $25(\mathrm{OH}) \mathrm{D}=19.66 \mathrm{ng} / \mathrm{mL}$ ), although the differences did not reach a significant level ( $\mathrm{p}$ $=0.94$ ) despite the fluctuations in serum vitamin $\mathrm{D}$ levels. The results of this study are in agreement with several published studies that addressed the relationship between seasonal changes and the status of vitamin D [45-48]. However, some studies have shown lower levels of serum 25(OH)D in winter, whereas, in a number of studies, the prevalence of vitamin D deficiency did not differ by seasonal changes and remained stable even in sunny climate [45-47,49]. These observations indicate that seasonal changes should not be considered the exclusive cause of vitamin D variations and that many other factors also contribute to the changes in serum vitamin D over different seasons [50-53].

The influence of marital status on vitamin D levels has not been studied in women. In our study, married women $(81.64 \%)$ had a higher prevalence of vitamin D inadequacy than single women $(74.54 \%)$. The difference observed was not statistically significant and can be attributed to the larger number of married females in the total population under study.

The higher prevalence of vitamin D inadequacy in the present study may be related to the low SES of our population, as RHUH is a governmental hospital, and patients visiting such hospitals have generally low SES. The importance of SES in the determination of vitamin D status was observed in the study performed on young participants [7] in a Lebanese study [8], in which participants from schools of high SES had better vitamin D status compared to those with low SES.

The current study raises the question: why in a sunny country like Lebanon where sufficient exposure to sunlight is guaranteed most of the year, deficiencies in vitamin D are surprisingly worryingly high.

One concern raised recently is the increased awareness of the risk of developing skin cancer.

Our lifestyle has changed; people are spending more time indoors, and when they go to the beach, they use sunscreen to prevent cancer, and they do not know that this way they are not getting vitamin D from UV rays and that they are at risk of vitamin D deficiency with its serious consequences.

It has been proven that wearing the veil affects people's vitamin D absorption, but young men have also high rates of vitamin D inadequacy, as demonstrated in our study and other studies.

Insufficient $25(\mathrm{OH}) \mathrm{D}$ intake is another reason that could explain the high prevalence of $25(\mathrm{OH}) \mathrm{D}$ inadequacy in the Lebanese population, as there is lack of vitamin D fortified food in Lebanon. Although, this factor was not addressed in our study, the relation between low vitamin D intake and vitamin D deficiency was elucidated in many other studies [44,54].

The present study provided an opportunity to assess several factors reported to have a relationship with vitamin D status in several studies.

Among these, only age showed a significant association with vitamin D status. Other studied factors (gender, parity, marital status, dress style, and season) did not show a significant relationship with vitamin D status in our study but were known to be independent predictors of low vitamin D, as reported in many studies.

Interlaboratory variation for the measurement of serum $25(\mathrm{OH}) \mathrm{D}$ may hamper comparison between results from different studies and may explain the difference in the prevalence between all subgroups of the Lebanese population. There are different methods for measuring 25(OH)D [44]. The competitive binding assay method used in our study gives slightly higher results than the HPLC method and the RIA method (DiaSorin assay) used in most of the Lebanese studies. Those differences in vitamin D assays could explain the higher levels of 25(OH)D observed in certain studies from the United States [43,55].

In addition to the conducted studies on the classical effects of vitamin D deficiency and its cognitive impacts, new studies are needed to determine the etiology of vitamin D deficiency in our population, to determine if there is a genetic component behind this markedly elevated rate of vitamin D deficiency, to establish reference values that truly represent the healthy Lebanese population, including seasonal variations, and to assess the different vitamin D supplementation regimens in order to select the best regimen that suits our population.

Finally, the facts elucidated in our study and in other studies require extreme awareness regarding vitamin D deficiency as a multigeneration crisis needing all possible attention.

However, no generalization can be deduced from our study since these results can be different among different age groups, living areas, and SES.

Limitations of our study include its cross-sectional, non-population-based nature, and the study included more women than men. Another limitation is the lack of data on body mass index (BMI), which is a major 
determinant of 25(OH)D. We, however, believe the results to be, to some extent, representative of findings in the Lebanese population in view of the comparable mean $25(\mathrm{OH}) \mathrm{D}$ values to those reported in other studies conducted on the Lebanese population. Furthermore, it capitalizes on a very large database from a referral academic governmental hospital, drawing patients from all parts of the country, that included a wide age span evaluated using, for the most part, the same $25(\mathrm{OH}) \mathrm{D}$ assay over a period of two years. However, because of the nature of the database, the study could not investigate other predictors of low $25(\mathrm{OH}) \mathrm{D}$ levels, such as BMI, medical conditions, medications, physical activity, dietary vitamin D intake, SES, educational level, and living area.

Moreover, it would be interesting to conduct a larger study to assess the magnitude of vitamin D deficiency at the national level taking into consideration all factors that might contribute to the difference in the prevalence of vitamin D deficiency among the subgroups of the Lebanese population; such a study can form a firm basis for evidence-based interventions at the population level.

\section{Conclusions}

In summary, this study shows that there is a high prevalence of vitamin D insufficiency in a sample of the Lebanese population, which is considered to some extent representative of the Lebanese population. Both males and females in all age groups were affected by this high prevalence of low vitamin D status. In addition, we demonstrated lower serum 25(OH)D levels and higher prevalence of vitamin D inadequacy, although not statistically significant, among veiled, married, and multiparous women compared to nonveiled, single, and uni/nulliparous women, and in winter months compared to summer months.

These findings, in addition to those of several other studies that demonstrated similar results, raise a health concern and imply urgent need for intervention at the national level, with preventive and educational plans to increase the awareness of the population about the vital role of vitamin D in order to minimize the complications of its deficiency. Preventive plan may include dietary enrichment or supplementation with vitamin D, encouraging a more active outdoor life style and advice about direct sun exposure.

Further studies and wide-scale cooperation of statistical data are a must. This is because numerous previous studies have been mostly conducted on small, non-population-based studies, which are standalone and seem to have failed to include all possible risk factors of different age groups with circadian and seasonal changes within the same study or country.

\section{Additional Information \\ Disclosures}

Human subjects: Consent was obtained or waived by all participants in this study. Animal subjects: All authors have confirmed that this study did not involve animal subjects or tissue. Conflicts of interest: In compliance with the ICMJE uniform disclosure form, all authors declare the following: Payment/services info: All authors have declared that no financial support was received from any organization for the submitted work. Financial relationships: All authors have declared that they have no financial relationships at present or within the previous three years with any organizations that might have an interest in the submitted work. Other relationships: All authors have declared that there are no other relationships or activities that could appear to have influenced the submitted work.

\section{References}

1. Holick MF, Krane SM, Pott JT: Calcium, phosphorusand bone metabolism: calcium-regulating hormones. Harrison's Principles of Internal Medicine. 14th Edition. Fauci AS, Braunwald E, Isselbacher KJ, et al. (ed): McGraw-Hill, New York, NY; 1998. 2214.

2. Parfitt AM, Gallagher JC, Heaney RP, Johnston CC, Neer R, Whedon GD: Vitamin D and bone health in the elderly. Am J Clin Nutr. 1982, 36:1014-31. 10.1093/ajcn/36.5.1014

3. Holick M: Vitamin D: the underappreciated D-lightfulhormone that is important for skeletal and cellular health. Curr Op Endocrinol Diabetes Obes. 2002, 9:87-98. 10.1097/00060793-200202000-00011

4. Lips P: Vitamin D deficiency and secondary hyperparathyroidism in the elderly: consequences for bone loss and fractures and therapeutic implications. Endocr Rev. 2001, 22:477-501. 10.1210/edrv.22.4.0437

5. Holick MF: The role of vitamin D for bone health and fracture prevention . Curr Osteoporos Rep. 2006, 4:96102. 10.1007/s11914-996-0028-z

6. Holick MF: The influence of vitamin D on bone health across the life cycle . J Nutr. 2005, 135:2726-7. 10.1093/jn/135.11.2726S

7. Gannagé-Yared MH, Chemali R, Yaacoub N, Halaby G: Hypovitaminosis D in a sunny country: relation to lifestyle and bone markers. J Bone Miner Res. 2000, 15:1856-62. 10.1359/jbmr.2000.15.9.1856

8. El-Hajj Fuleihan G, Nabulsi M, Choucair M, et al.: Hypovitaminosis D in healthy schoolchildren. Pediatrics. 2001, 107:53. 10.1542/peds.107.4.e53

9. Gannagé-Yared MH, Brax H, Asmar A, Tohmé A: Statut Vitaminique D des sujets ages. Etude de la population libanaise [Vitamin D status in aged subjects. Study of a Lebanese population]. Presse Med. 1998, 27:900-4.

10. Gannagé-Yared MH, Maalouf G, Khalife S, et al.: Prevalence and predictors of vitamin D inadequacy amongst Lebanese osteoporotic women. Br J Nutr. 2009, 101:487-91. 10.1017/S0007114508023404 
11. Lips P, Hosking D, Lippuner K, et al.: The prevalence of vitamin D inadequacy amongst women with osteoporosis: an international epidemiological investigation. J Intern Med. 2006, 260:245-54. 10.1111/j.1365-2796.2006.01685.x

12. Baroncelli GI, Bereket A, El Kholy M, et al.: Rickets in the Middle East: role of environment and genetic predisposition. J Clin Endocrinol Metab. 2008, 93:1743-50. 10.1210/jc.2007-1413

13. Holick MF: Vitamin D deficiency. N Engl J Med. 2007, 357:266-81. 10.1056/NEJMra070553

14. Hollis BW: Assessment and interpretation of circulating 25-hydroxyvitamin D and 1,25-dihydroxyvitamin D in the clinical environment. Endocrinol Metab Clin North Am. 2010, 39:271-86. 10.1016/j.ecl.2010.02.012

15. DiaSorin Inc. LIASON 510(K) FDA submission. (2013). Accessed: January 7, 2013: http://www.accessdata.fda.gov/cdrh_docs/reviews/K071480.pdf.

16. Lensmeyer G, Poquette M, Wiebe D, Binkley N: The C-3 epimer of 25-hydroxyvitamin D(3) is present in adult serum. J Clin Endocrinol Metab. 2012, 97:163-8. 10.1210/jc.2011-0584

17. Terry AH, Sandrock T, Meikle AW: Measurement of 25-hydroxyvitamin D by the Nichols ADVANTAGE, DiaSorin LIAISON, DiaSorin RIA, and liquid chromatography-tandem mass spectrometry. Clin Chem. 2005, 51:1565-6. 10.1373/clinchem.2005.054239

18. Wallace AM, Gibson S, de la Hunty A, Lamberg-Allardt C, Ashwell M: Measurement of 25-hydroxyvitamin D in the clinical laboratory: current procedures, performance characteristics and limitations. Steroids. 2010, 75:477-88. 10.1016/j.steroids.2010.02.012

19. de Koning L, Al-Turkmani MR, Berg AH, Shkreta A, Law T, Kellogg MD: Variation in clinical vitamin D status by DiaSorin Liaison and LC-MS/MS in the presence of elevated 25-OH vitamin D2. Clin Chim Acta. 2013, 415:54-8. 10.1016/j.cca.2012.09.002

20. Farrell CJ, Martin S, McWhinney B, Straub I, Williams P, Herrmann M: State-of-the-art vitamin D assays: a comparison of automated immunoassays with liquid chromatography-tandem mass spectrometry methods. Clin Chem. 2012, 58:531-42. 10.1373/clinchem.2011.172155

21. New vitamin D blood tests are often highly inaccurate, researchers say . (2012). Accessed: January 7, 2013 : http://www.eurekalert.org/pub_releases/2012-06/tes-tnv062412.php.

22. Measurements of 25-OH vitamin D concentrations . (2009). Accessed: January 7, 2013: http://www.cap.org/apps/docs/committees/chemistry/measurements_25_OH_vitamin_d.pdf.

23. Carter GD, Jones JC, Shannon J, Williams EL, Jones G, Kaufmann M, Sempos C: 25-Hydroxyvitamin D assays: potential interference from other circulating vitamin D metabolites. J Steroid Biochem Mol Biol. 2016, 164:134-8. 10.1016/j.jsbmb.2015.12.018

24. Moussavi M, Heidarpour R, Aminorroaya A, Pournaghshband Z, Amini M: Prevalence of vitamin D deficiency in Isfahani high school students in 2004. Horm Res. 2005, 64:144-8. 10.1159/000088588

25. Siddiqui AM, Kamfar HZ: Prevalence of vitamin D deficiency rickets in adolescent school girls in Western region, Saudi Arabia. Saudi Med J. 2007, 28:441-4.

26. Dahifar H, Faraji A, Ghorbani A, Yassobi S: Impact of dietary and lifestyle on vitamin D in healthy student girls aged 11-15 years. J Med Invest. 2006, 53:204-8. 10.2152/jmi.53.204

27. Kimball S, El-Hajj Fuleihan G, Vieth R: Vitamin D: a growing perspective . Crit Rev Clin Lab Sci. 2008, 45:339-414. 10.1080/10408360802165295

28. Holick MF: Vitamin D: Physiology, Molecular Biology, and Clinical Applications. Humana Press, Clifton, NJ; 2010.

29. van der Wielen RP, Löwik MR, van den Berg H, et al.: Serum vitamin D concentrations among elderly people in Europe. Lancet. 1995, 346:207-210. 10.1016/s0140-6736(95)91266-5

30. Scharla SH: Prevalence of subclinical vitamin D deficiency in different European countries . Osteoporos Int. 1998, 8:7-12. 10.1007/pl00022726

31. Mithal A, Wahl DA, Bonjour JP, et al.: Global vitamin D status and determinants of hypovitaminosis D . Osteoporos Int. 2009, 20:1807-20. 10.1007/s00198-009-0954-6

32. Holick MF, Siris ES, Binkley N, et al.: Prevalence of Vitamin D inadequacy among postmenopausal North American women receiving osteoporosis therapy. J Clin Endocrinol Metab. 2005, 90:3215-24. 10.1210/jc.2004-2364

33. Pappas A, Fantasia J, Chen T: Age and ethnic variations in sebaceous lipids . Dermatoendocrinol. 2013, 5:319-24. 10.4161/derm.25366

34. Oberg J, Jorde R, Almås B, Emaus N, Grimnes G: Vitamin D deficiency and lifestyle risk factors in a Norwegian adolescent population. Scand J Public Health. 2014, 42:593-602. 10.1177/1403494814541593

35. el-Sonbaty MR, Abdul-Ghaffar NU: Vitamin D deficiency in veiled Kuwaiti women . Eur J Clin Nutr. 1996, 50:315-8.

36. Dawodu A, Absood G, Patel M, Agarwal M, Ezimokhai M, Abdulrazzaq Y, Khalayli G: Biosocial factors affecting vitamin D status of women of childbearing age in the United Arab Emirates. J Biosoc Sci. 1998, 30:431-7. 10.1017/s0021932098004313

37. Alagöl F, Shihadeh Y, Boztepe H, Tanakol R, Yarman S, Azizlerli H, Sandalci O: Sunlight exposure and vitamin D deficiency in Turkish women. J Endocrinol Invest. 2000, 23:173-7. 10.1007/BF03343702

38. Ghannam NN, Hammami MM, Bakheet SM, Khan BA: Bone mineral density of the spine and femur in healthy Saudi females: relation to vitamin D status, pregnancy, and lactation. Calcif Tissue Int. 1999, 65:238. 10.1007/s002239900652

39. Kaykhaei MA, Hashemi M, Narouie B, Shikhzadeh A, Rashidi H, Moulaei N, Ghavami S: High prevalence of vitamin D deficiency in Zahedan, southeast Iran. Ann Nutr Metab. 2011, 58:37-41. 10.1159/000323749

40. Hovsepian S, Amini M, Aminorroaya A, Amini P, Iraj B: Prevalence of vitamin D deficiency among adult population of Isfahan City, Iran. J Health Popul Nutr. 2011, 29:149-55. 10.3329/jhpn.v29i2.7857

41. Fouda MA, Turkestani IZ, Almusharraf S, et al.: Extremely high prevalence of maternal and neonatal vitamin D deficiency in the Arab population. Neonatology. 2017, 112:225-30. 10.1159/000475704

42. Dawson-Hughes B, Harris SS, Dallal GE: Plasma calcidiol, season, and serum parathyroid hormone concentrations in healthy elderly men and women. Am J Clin Nutr. 1997, 65:67-71. 10.1093/ajcn/65.1.67

43. Jacques PF, Felson DT, Tucker KL, Mahnken B, Wilson PW, Rosenberg IH, Rush D: Plasma 25hydroxyvitamin D and its determinants in an elderly population sample. Am J Clin Nutr. 1997, 66:929-36. 
10.1093/ajcn/66.4.929

44. Salamone LM, Dallal GE, Zantos D, Makrauer F, Dawson-Hughes B: Contributions of vitamin D intake and seasonal sunlight exposure to plasma 25-hydroxyvitamin D concentration in elderly women. Am J Clin Nutr. 1994, 59:80-6. 10.1093/ajcn/59.1.80

45. Costanzo PR, Elías NO, Kleiman Rubinsztein J, García Basavilbaso NX, Piacentini R, Salerni HH: Variaciones estacionales de $25(\mathrm{OH})$ vitamina D en jóvenes sanos y su asociación con la radiación ultravioleta en Buenos Aires [Ultraviolet radiation impact on seasonal variations of serum 25-hydroxy-vitamin D in healthy young adults in Buenos Aires]. Medicina (B Aires). 2011, 71:336-42.

46. González-Parra E, Avila PJ, Mahillo-Fernández I, Lentisco C, Gracia C, Egido J, Ortiz A: High prevalence of winter 25-hydroxyvitamin D deficiency despite supplementation according to guidelines for hemodialysis patients. Clin Exp Nephrol. 2012, 16:945-51. 10.1007/s10157-012-0642-2

47. Kashi Z, Saeedian FS, Akha O, Gorgi MA, Emadi SF, Zakeri H: Vitamin D deficiency prevalence in summer compared to winter in a city with high humidity and a sultry climate. Endokrynol Pol. 2011, 62:249-51.

48. Shoben AB, Kestenbaum B, Levin G, Hoofnagle AN, Psaty BM, Siscovick DS, de Boer IH: Seasonal variation in 25-hydroxyvitamin D concentrations in the cardiovascular health study. Am J Epidemiol. 2011, 174:1363-72. 10.1093/aje/kwr258

49. Rajakumar K, Holick MF, Jeong K, et al.: Impact of season and diet on vitamin D status of African American and Caucasian children. Clin Pediatr (Phila). 2011, 50:493-502. 10.1177/0009922810397334

50. Macdonald HM, Mavroeidi A, Barr RJ, Black AJ, Fraser WD, Reid DM: Vitamin D status in postmenopausal women living at higher latitudes in the UK in relation to bone health, overweight, sunlight exposure and dietary vitamin D. Bone. 2008, 42:996-1003. 10.1016/j.bone.2008.01.011

51. Farrar MD, Kift R, Felton SJ, et al.: Recommended summer sunlight exposure amounts fail to produce sufficient vitamin D status in UK adults of South Asian origin. Am J Clin Nutr. 2011, 94:1219-24. 10.3945/ajcn.111.019976

52. Carnevale V, Modoni S, Pileri M, et al.: Longitudinal evaluation of vitamin D status in healthy subjects from southern Italy: seasonal and gender differences. Osteoporos Int. 2001, 12:1026-30. 10.1007/s001980170012

53. Shea MK, Houston DK, Tooze JA, et al.: Correlates and prevalence of insufficient 25-hydroxyvitamin D status in black and white older adults: the health, aging and body composition study. J Am Geriatr Soc. 2011, 59:1165-74. 10.1111/j.1532-5415.2011.03476.x

54. Mansoor S, Habib A, Ghani F, et al.: Prevalence and significance of vitamin D deficiency and insufficiency among apparently healthy adults. Clin Biochem. 2010, 43:1431-5. 10.1016/j.clinbiochem.2010.09.022

55. Lips P, Chapuy MC, Dawson-Hughes B, Pols HA, Holick MF: An international comparison of serum 25hydroxyvitamin D measurements. Osteoporos Int. 1999, 9:394-7. 10.1007/s001980050162 